\title{
Seasonal cycle of the snow coverage in the former Soviet Union and its relation with atmospheric circulation
}

\author{
KUNIO RIKIISHI, JUNKo SAKAKIBARA \\ Department of Earth and Environmental Sciences, Hirosaki University, Hirosaki 036-8561, Japan \\ E-mail:rikiishi@cc.hirosaki-u.ac.jp
}

\begin{abstract}
Historical snow-depth observations in the former Soviet Union (FSU) during the period September 1960-August 1984 have been analyzed in order to understand the seasonal cycle of snow coverage in the FSU. Snow cover first appears in September in northeastern regions, and spreads over the entire territory before early January. Snowmelt begins in mid-January in the southern regions and then snow cover retreats rapidly northward until it disappears completely before late June. Northward of $60^{\circ} \mathrm{N}$, the land surface is snow-covered for more than half the year. The longest snow-cover duration is observed on the central Siberian plateau (about 9.5 months) and along the Arctic coastal regions (about 8.5 months). One of the most conspicuous features of the snow coverage in the FSU is that the length of the snow-accumulation period differs considerably from region to region (2-7 months), while the length of the snowmelt period is rather short and uniform over almost the entire territory (1-2 months). Although the maximum snow depths are $20-50 \mathrm{~cm}$ in most regions of the FSU, they exceed $80 \mathrm{~cm}$ in the mountainous regions in central Siberia, Kamchatka peninsula, and along the Yenisei river valley. Values for the maximum snow depth are very small along the Lena river valley in spite of the air temperature being extremely low in winter. By calculating correlation coefficients between the snowfall intensities and the sea-level pressures or $500 \mathrm{hPa}$ heights, it is shown that deep snow along the Yenisei river valley is caused by frequent migration of synoptic disturbances from the Arctic Ocean. Snowfalls along the Lena river valley are also caused by traveling disturbances from the Arctic Ocean. Snow accumulation is suppressed after the Arctic Ocean has been frozen.
\end{abstract}

\section{INTRODUCTION}

The former Soviet Union (FSU) covers a huge area (35$70^{\circ} \mathrm{N}, 25-180^{\circ} \mathrm{E}$ ), and the entire territory is snow-covered in mid-winter. The FSU consists of six regions: the European Russian plain $\left(20-60^{\circ} \mathrm{E}\right.$, north of $\left.50^{\circ} \mathrm{N}\right)$, the western Siberian plain $\left(60-95^{\circ} \mathrm{E}\right.$, north of $\left.50^{\circ} \mathrm{N}\right)$, central Siberia $\left(95-135^{\circ} \mathrm{E}\right.$ ), eastern Siberia (from $135^{\circ} \mathrm{E}$ eastwards), the southwestern region (from $50^{\circ} \mathrm{N}$ southwards and $50^{\circ} \mathrm{E}$ westwards) and central Asia $\left(50-90^{\circ} \mathrm{E}\right.$, south of $\left.50^{\circ} \mathrm{N}\right)$. It is widely believed that snow cover plays an important role in the climate system through the snow-albedo feedback process and through its function as an insulator between the atmosphere and land surface. Because of its huge area, the Eurasian continent exerts a great influence on the climate variation in the Northern Hemisphere. Indeed, variations of snow-cover extent in the Eurasian continent are closely related to the activities of the Indian monsoon (Hahn and Shukla, 1976; Yang and Xu, 1994).

Our knowledge of the seasonal snow coverage in the FSU was very limited until recent years (Lydolph, 1977). Since the National Snow and Ice Data Center (NSIDC), Boulder, CO, U.S.A., compiled the historical snow-depth observations in the FSU (Barry and others, 1993), important studies have been published. Fallot and others (1997) examined relationships among the mean cold-season temperature, precipitation and snow depth during the last 100 years and discussed long-term variations of snow depth in connec- tion with recent global warming. Ye and others (1998) studied spatial variation patterns of winter snow accumulation by using principal component analysis. Kripalani and Kulkarni (1999) found a negative correlation between the snow depths in western Eurasia in wintertime and the Indian monsoon in summertime. Brown (2000) found that the decreasing trend in snow-cover extent is associated with the increasing trend in air temperature in springtime.

The objective of this paper is to understand the longterm mean seasonal cycle of snow coverage in the FSU based on the extensive dataset. We will concentrate on the dates of the start and end of snow cover and the maximum snow depth, and on the lengths of snow-cover season, snowaccumulation period and snowmelting period. To explain some remarkable characteristics of the observed snow-depth distribution, snowfall intensities derived from the snowdepth data will be examined in connection with the atmospheric circulation.

\section{HISTORICAL SNOW-DEPTH OBSERVATIONS IN THE FSU}

The NSIDC compiled and released the dataset of historical daily snow-depth observations from 284 stations in the FSU (see Fig. 1). Obviously, the station density reflects the population density; more stations are located at $50-65^{\circ} \mathrm{N}$, and in the western half of the territory. Note that there are few stations in the Arctic coastal regions. Although the original 


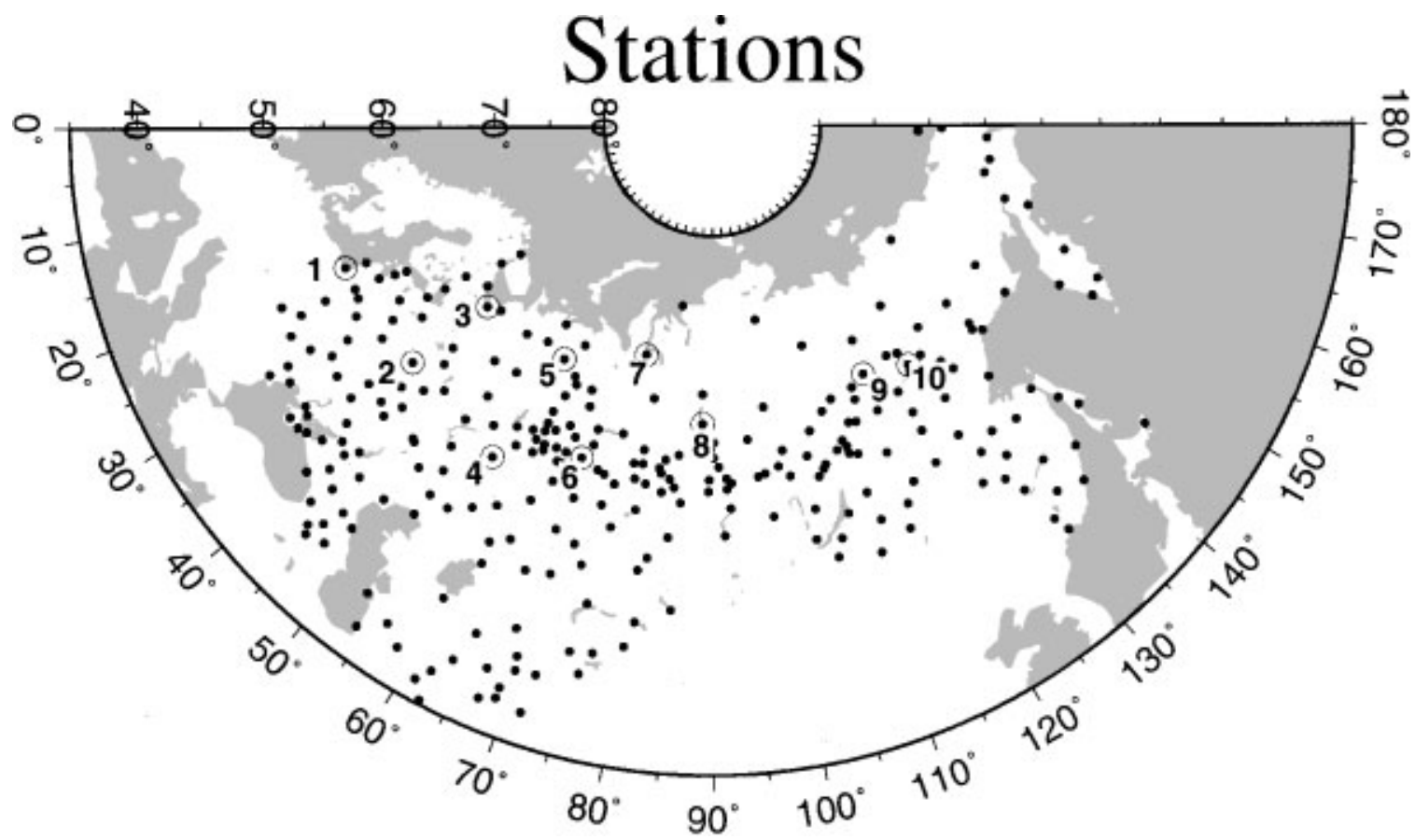

Fig. 1. Geographical distribution of the 284 snow-depth observation stations in the FSU. Names of some representative stations are 1. Kaliningrad, 2. Moskva, 3. Onega, 4. Ufa, 5. Pechora, 6. Tubol'sk, 7. Mys-Kamennyj, 8. Verhne-Imbatskoye, 9. Viljujsk, 10. Yakutsk. The mean seasonal cycles of snow depth for these stations are presented in Figure 2.

dataset covers 1881-1985, we deal with the period September 1960-August 1984, when fewest data were missing. The original dataset included many questionable data, some of which were corrected through the quality-checking processes of the NSIDC (Barry and others, 1993; Fallot and others, 1997; Kripalani and Kulkarni, 1999). In this study we use only the data in the most reliable rank. Nevertheless, some questionable data remain. Consequently, the original time series are compared with their 30 day moving averages, and if differences are $>50 \mathrm{~cm}$ the data are rejected as outliers.

For study of the mean seasonal cycle of snow coverage, daily data are too fine and monthly data too rough in time resolution. Consequently, time series of 5 day mean snow depths are used here. One month is divided into six pentads (a pentad $=5$ days $)$, and the snow depths are given at intervals of a pentad. Values for the first to fifth pentads represent averages over exactly 5 days in cases of no missing data. Values for the sixth pentad usually represent 5 or 6 day averages depending on the month. Values for the sixth pentad of February represent 3 day averages for civil years or 4 day averages for leap years. Where only one datum was available for a pentad, the data were abandoned.

\section{SEASONAL GHANGE OF SNOW DEPTH AND THE MAXIMUM SNOW DEPTH}

The mean seasonal cycle of snow depth is shown in Figure 2 for ten representative stations; locations are indicated in Figure 1. Snow depth increases significantly in October in central Siberia (Viljujsk, Yakutsk) and along the Arctic coastal regions (Onega, Pechora, Mys-Kamennyj), and in November in the European Russian plain (Kaliningrad, Moskva). The maximum snow depths are very large in the western Siberian plain (Verhne-Imbatskoye: $90 \mathrm{~cm}$ ) and along the Arctic coastal regions (Pechora: $70 \mathrm{~cm}$; Mys Kamennyj: $65 \mathrm{~cm}$ ). Note that these stations are close to the
Arctic Ocean which is a huge source of water vapor. By contrast, the maximum snow depths are very small in the European Russian plain (Kaliningrad: $10 \mathrm{~cm}$ ) and Lena river valley, central Siberian lowland (Tubol'sk: $30 \mathrm{~cm}$; Yakutsk: $30 \mathrm{~cm}$ ), which are located far away from source regions of water vapor. Along the Lena river valley (Viljujsk and Yakutsk), snowfall begins early in September (see Fig. 3), but little snow accumulates after December. We notice in Figure 2 that snow in the FSU accumulates for 4-7 months and melts away in about 1.5 months.

Geographical distribution of the maximum snow depths at the 284 stations is shown in Figure 3 (see Fig. 5 for the corresponding dates). In general, the maximum snow depths are larger in high-latitude regions $(\sim 50 \mathrm{~cm})$ and smaller in low-latitude regions $(\sim 20 \mathrm{~cm})$. Larger values are observed in high mountain regions of the Kamchatka peninsula $(\sim 90 \mathrm{~cm})$ and central Siberian plateau $(\sim 70 \mathrm{~cm})$. The districts along the Yenisei river valley $(\sim 80 \mathrm{~cm})$ are also large in spite of the low altitude. On the other hand, the maximum snow depths are $30-40 \mathrm{~cm}$ along the Lena river valley which is known to be the coldest region in the Northern Hemisphere. These facts imply that the maximum snow depths are controlled not only by air temperature and topography but also by atmospheric circulation which brings water vapor.

\section{DATES OF SNOW-GOVER START, SNOW-GOVER END AND MAXIMUM SNOW DEPTH}

Roughly speaking, snow cover appears in September and disappears in July in the FSU. The seasonal cycle of snow cover can be characterized by the dates of snow-cover start and end, and of the maximum snow depth. Figure 4 shows a geographical distribution of the dates when snow depths exceeded $1 \mathrm{~cm}$ (snow-cover start). It is shown that snow cover first appears in the central Siberian plateau (around $65^{\circ} \mathrm{N}$, $115^{\circ} \mathrm{E}$ ) in late August. The mountainous parts of eastern 

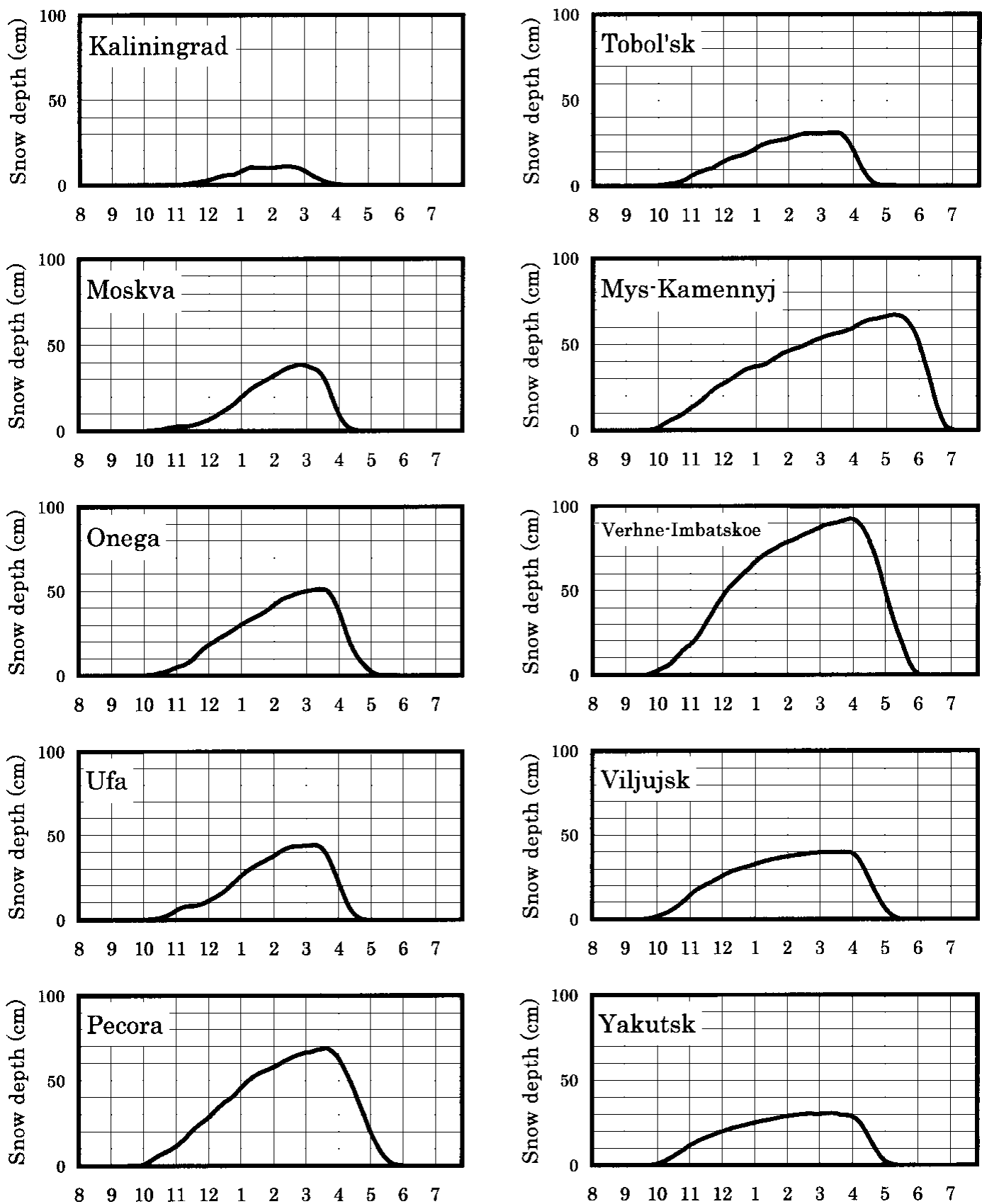

Fig. 2. Mean seasonal cycles of snow depth for the ten representative stations ( see Fig. 1 for locations).

Siberia and Arctic Ocean coastal regions are also snowcovered by the end of September. The area spreads rapidly towards south and west, and the regions north of $55^{\circ} \mathrm{N}$ are mostly snow-covered by the end of October. Then the area slowly extends southward to the southwestern region (near the Black and Caspian Seas) by the end of December. It takes about 4 months for the snow-covered area to extend over the entire territory.

Figure 5 shows a geographical distribution of the dates of maximum snow depth. The maximum snow depths appear during late February to late March except for the Arctic coastal regions (mid-April) and the southwestern region (late January to mid-February). Obviously the date of the maximum snow depth corresponds to the date when the snowmelt starts, so we can assume that it is the date when the daily mean air temperature rises above the freezing point.

Figure 6 shows a geographical distribution of the dates when snow depths become zero (snow-cover end). Snow cover disappears first in the southwestern region (near the Black and Caspian Seas) in early March and lastly in the Arctic coastal regions in mid-June. The snowmelt line (the border between the snow-cover and snow-free areas in the snowmelting period) is generally parallel to longitude lines, suggesting that the solar radiation is most important for snowmelting. The snowmelt line travels northward for 4 months at a fairly uniform speed.

\section{LENGTHS OF THE SNOW-GOVER SEASON, SNOW- ACGUMULATION PERIOD AND SNOWMELTING PERIOD}

Lengths of the snow-cover season, snow-accumulation period and snowmelting period are also important parameters for the seasonal cycle of snow cover. Figure 7 shows a geographical distribution of the lengths of the snow-cover season. Generally, the snow-cover duration is longer in 


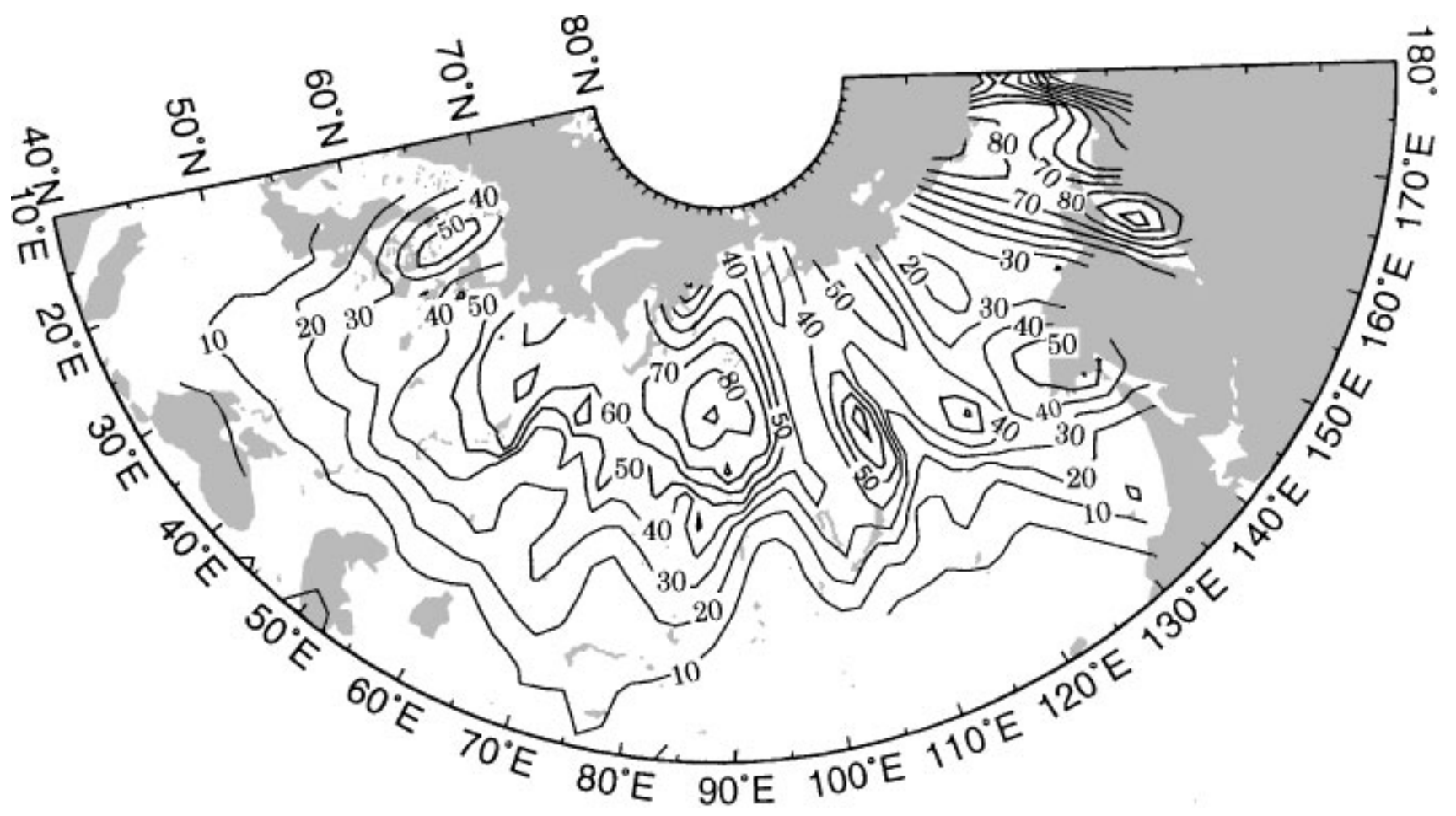

Fig. 3. Geographical distribution of the mean maximum snow depths at the 284 stations. Isopleths are given at intervals of $10 \mathrm{~cm}$.

high-latitude regions and shorter in low-latitude regions. Northward of $60^{\circ} \mathrm{N}$, the land surface is snow-covered for more than half the year. The longest duration occurs in the central Siberian plateau (about 9.5 months) and along the Arctic coastal regions (about 8.5 months), whereas in the southwestern region the snow-cover duration is 4 months or less.

The duration between the dates of maximum snow depth and snow-cover start marks the snow-accumulation period. It is shown in Figure 8, and we see a good re- semblance to the snow cover in Figure 7. The snowaccumulation durations are longer (6 months or more) in eastern Siberia and the Arctic coastal region, and shorter (3 months or less) in the southwestern region. Conversely, the duration between the snow-cover end and the maximum snow depth marks the snowmelting period. It is described in Figure 9, and the distribution is found to be surprisingly uniform: mostly within 9-12 pentads (1.52 months). This antisymmetry between the snowaccumulation and snowmelt durations is one of the most

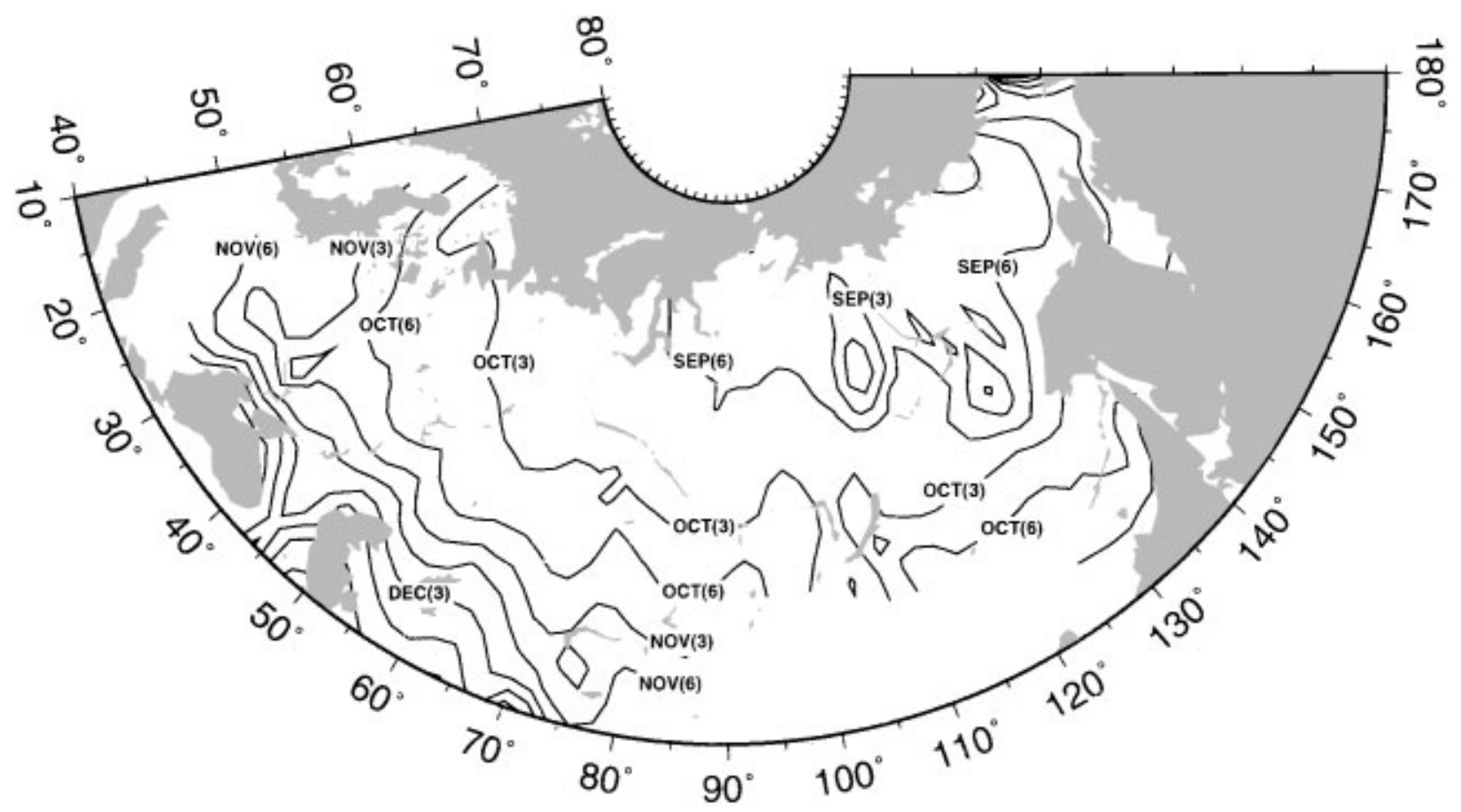

Fig. 4. Geographical distribution of the mean dates of snow-cover start. Isopleths are given at intervals of a half-month. Numbers in parentheses are pentad numbers. 


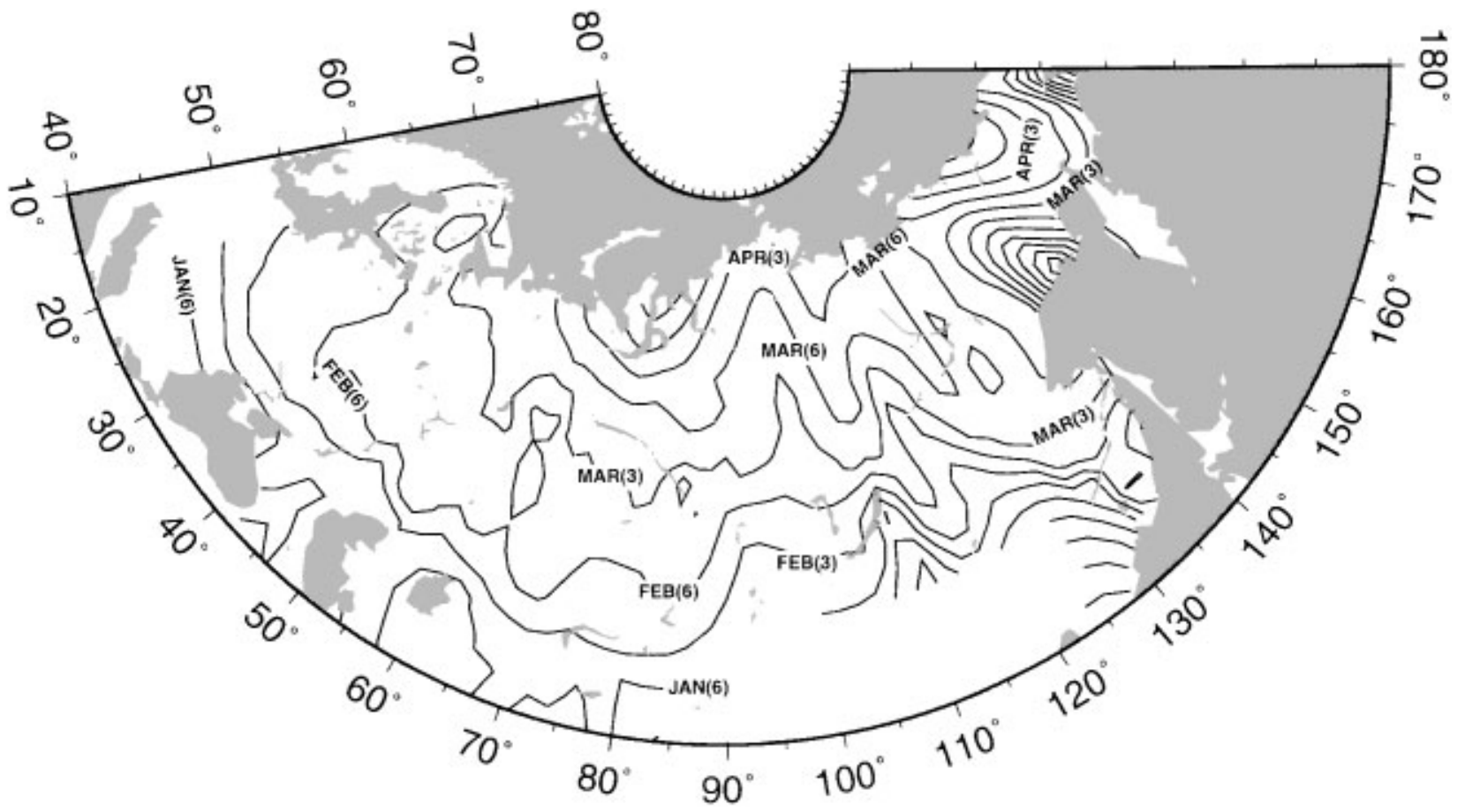

Fig. 5. Geographical distribution of the mean dates of maximum snow depths. Isopleths are given at intervals of a half-month.

Numbers in parentheses are pentad numbers.

conspicuous features of the seasonal snow coverage in the FSU.

\section{SNOWFALL INTENSITY IN RELATION TO ATMOSPHERIC GIRGULATION}

Snowfall intensity can be derived as the difference of snow depths between two time-steps. Suppose $x(t)$ represents the snow depth at the pentad $t$, then the increment (or difference) $y(t)=x(t+1)-x(t-1)$ represents the snowfall amount during the two pentads (10 days) if the value is positive, or the snowmelt amount if the value is negative. The following results are derived. The maximum snowfall intensities $(10 \mathrm{~cm}$ per 10 days at most) are found from midOctober to early December in central and eastern Siberia, and from mid-December to mid-January in the European Russian plain. On the other hand, the maximum snowmelt intensities (mostly $10-20 \mathrm{~cm}$ per 10 days) are observed during early April to mid-May throughout the FSU.

Spatial correlation of the snowfall or snowmelt can be

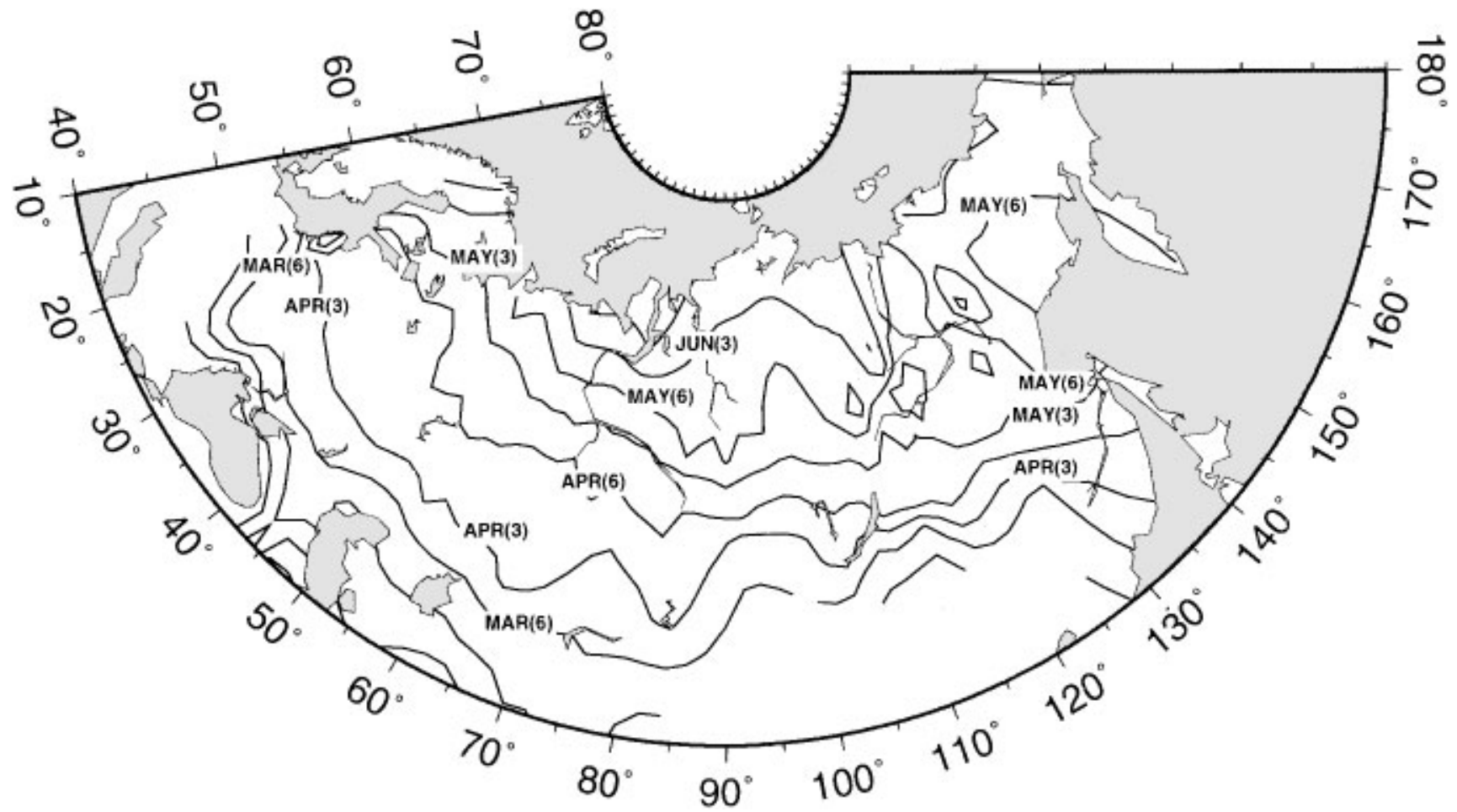

Fig. 6. Geographical distribution of the mean dates of snow-cover end. Isopleths are given at intervals of a half-month. Numbers in parentheses are pentad numbers. 


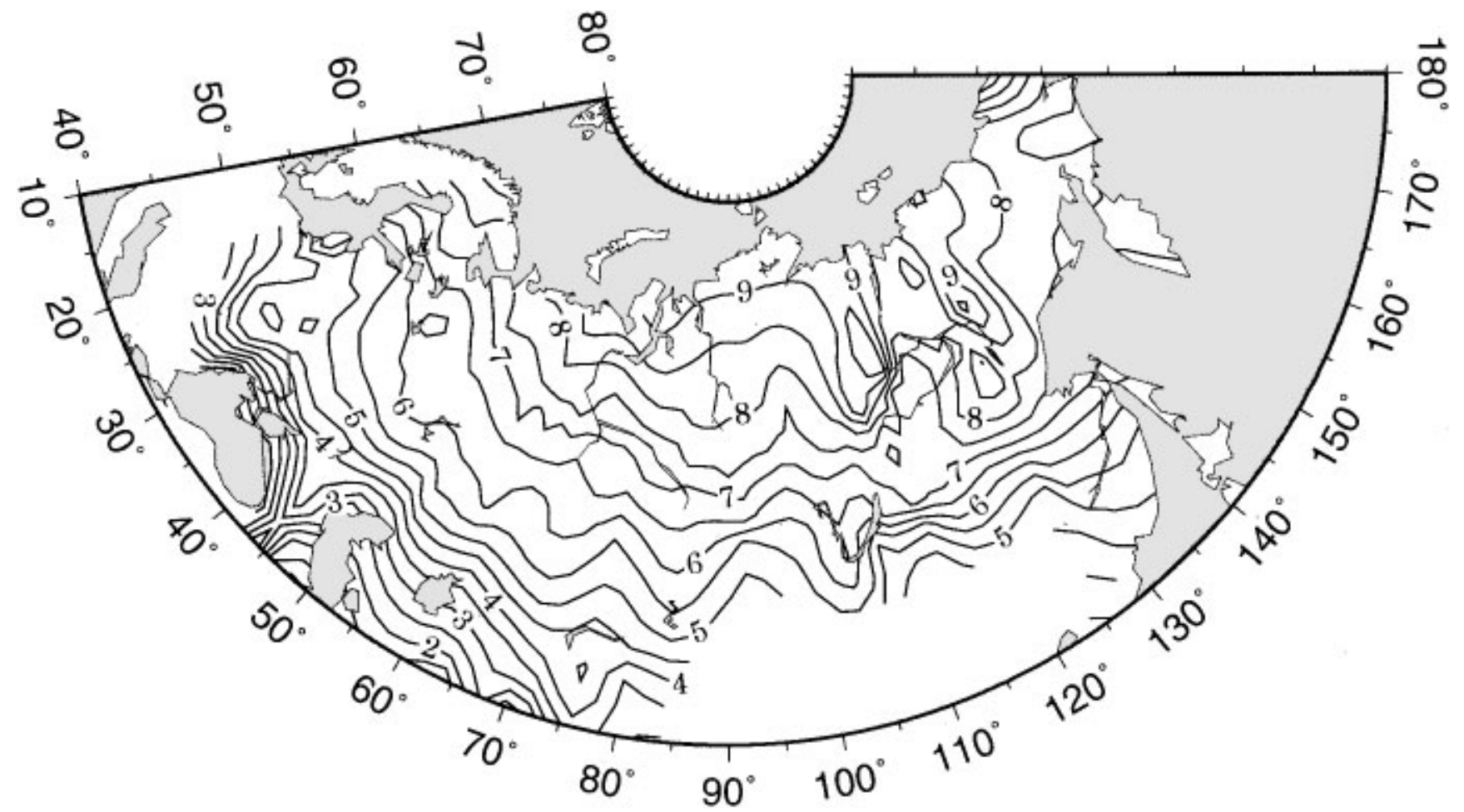

Fig. 7. Geographical distribution of the mean lengths of snow-cover season. Isopleths are given at intervals of a half-month.

estimated by calculating correlation coefficients between the time series $y(t)$ at the reference station and those for all the others. For the snow-accumulation period, it has been found that high correlations are only seen in a rather small area around the reference station. For the snowmelting period, on the other hand, high correlations are observed in a zonal area along the latitude of the reference station. This suggests that snowfall in the FSU tends to be strongly controlled by both atmospheric circulation and local topog- raphy, while contributions of solar radiation are large for snowmelt.

In order to examine how the heavy snowfall is related to the atmospheric circulation and how the relation changes from one region to another, we have calculated correlation coefficients between the snowfall intensities $y(t)$ at the reference station and the sea-level pressures $\operatorname{SLP}(t)$ or $500 \mathrm{hPa}$ heights $Z 500(t)$ over the entire Northern Hemisphere. The meteorological data used here have been objectively

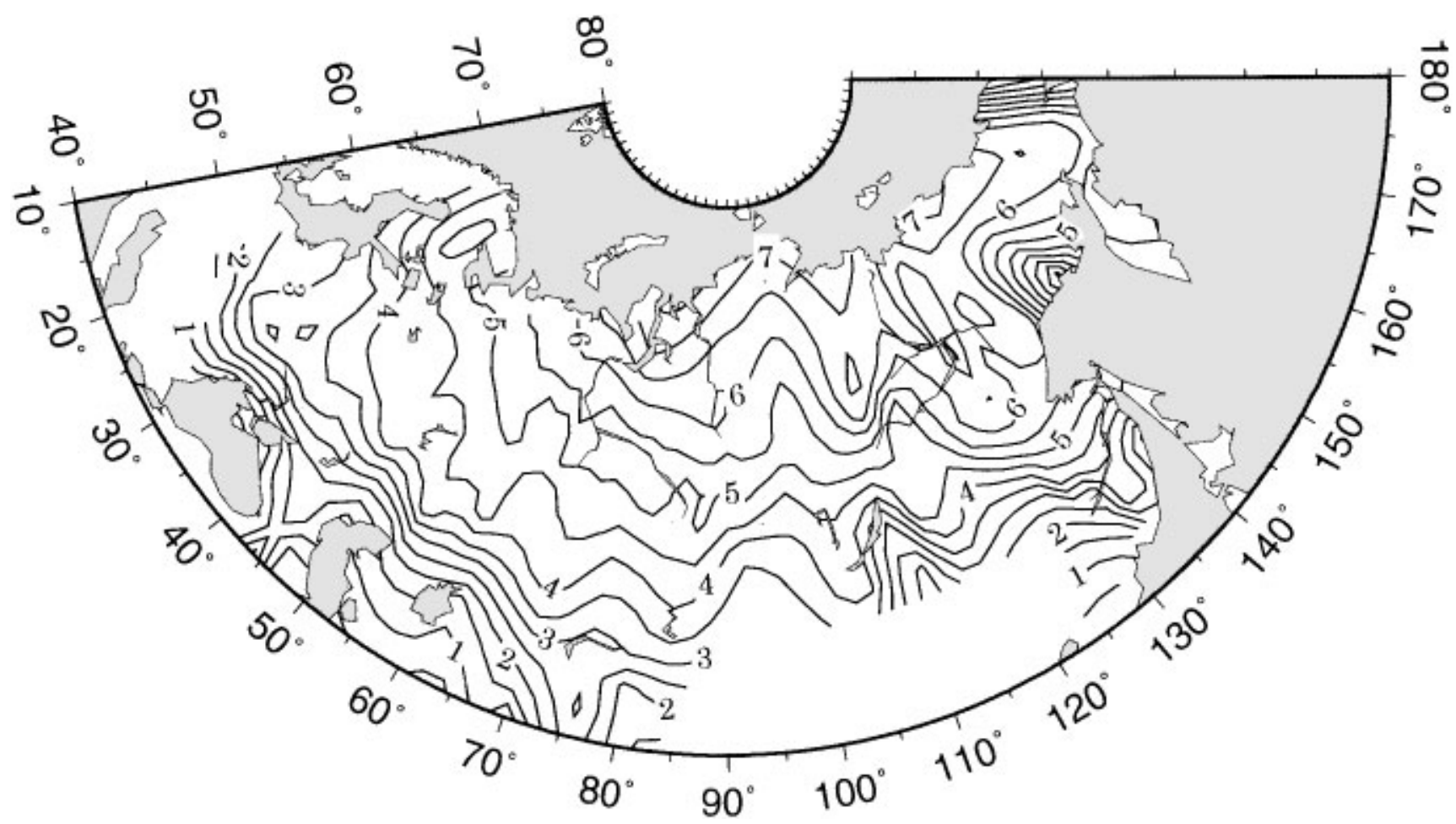

Fig. 8. Geographical distribution of the mean lengths of snow-accumulation period. Isopleths are given at intervals of a half-month. 


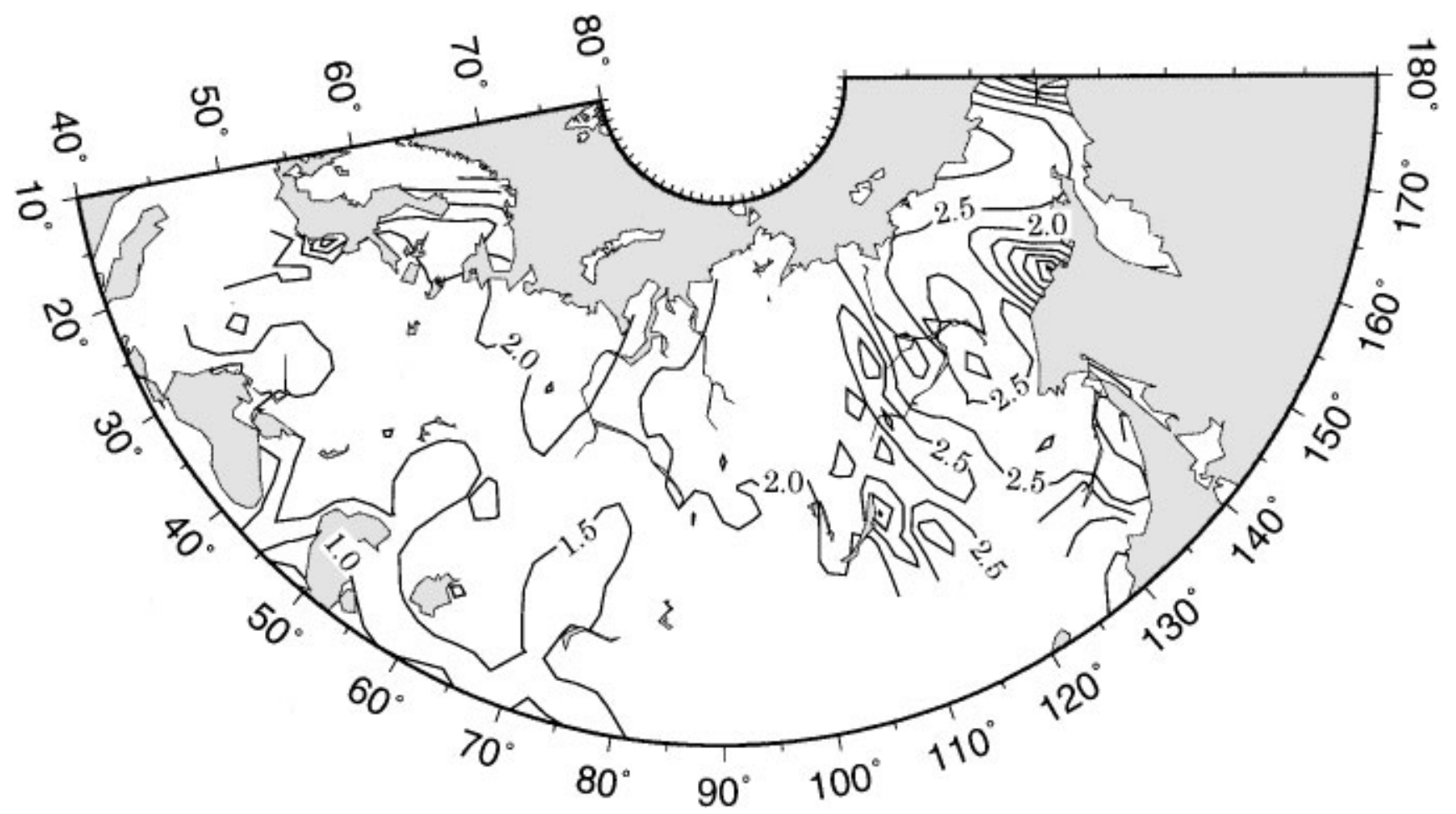

Fig. 9. Geographical distribution of the mean lengths of snowmelting period. Isopleths are given at intervals of a half-month.

analyzed by the U.S. National Meteorological Genter (NMC) for equally spaced grids of $47 \times 51$ on a polar stereo projection. Original data obtained twice a day are runningaveraged over 5 days for the period 1960-84 so that we can directly relate them with the snow-depth data. Data from December to February were taken into account so as to include the date of the maximum snowfall intensity in the analysis. Note that anomalies from the 25 year mean value are used to calculate correlation coefficients.
Figure $10 \mathrm{a}$ and b show correlation coefficients between the snowfall intensities at Moskva during December-February and the $500 \mathrm{hPa}$ heights and sea-level pressures, respectively, at all NMC gridpoints. The figure is equivalent to the fields of $500 \mathrm{hPa}$ height anomaly and sea-level pressure anomaly for cases of strong snowfall intensities. In Figure 10b, high negative correlations (maximum -0.41) are observed around Moskva, implying that snowfalls there are primarily caused by low pressure. High negative
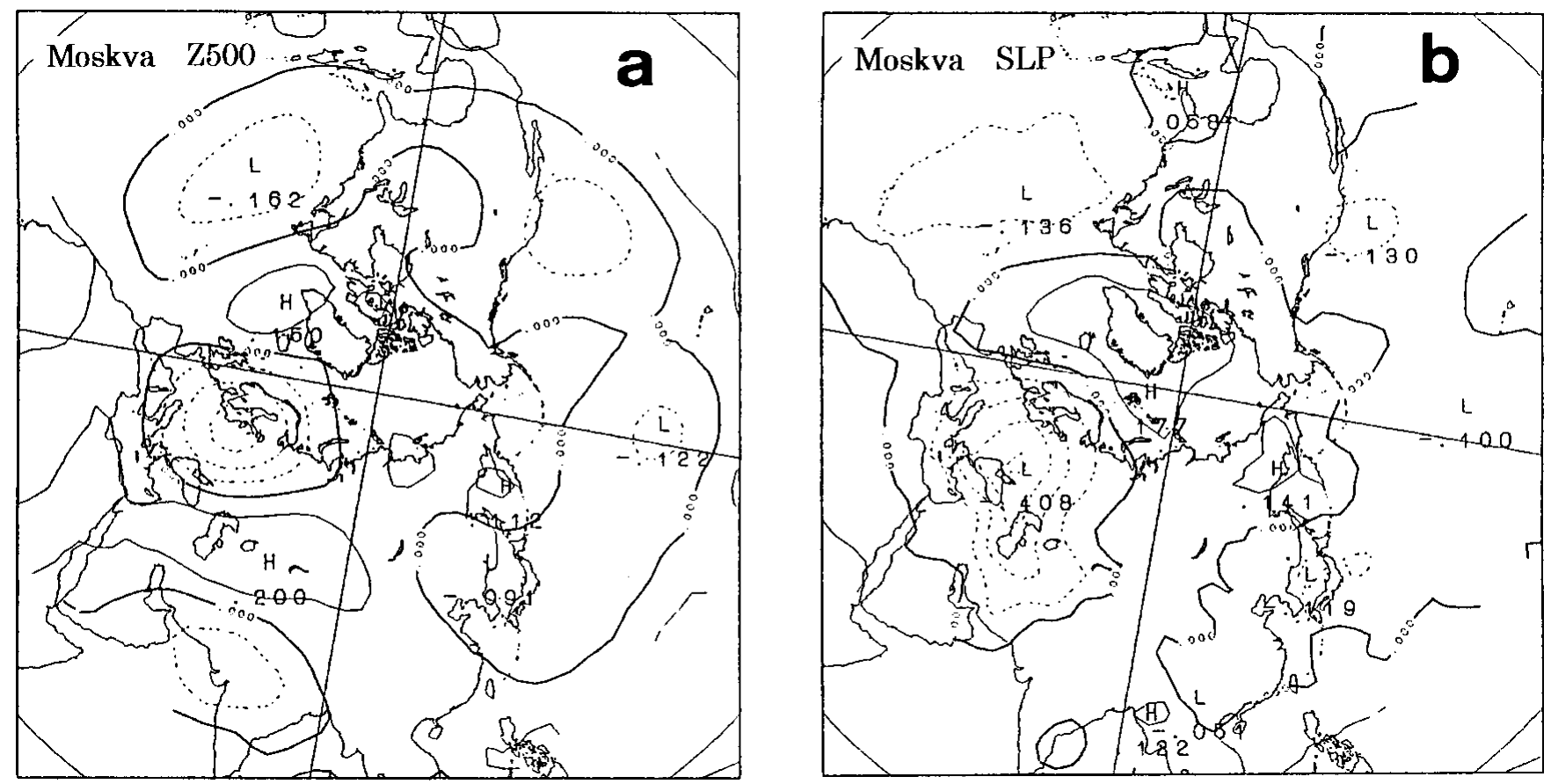

Fig. 10. Correlation coefficients between the snowfall intensities at Moskva $\left(55.8^{\circ} \mathrm{N}, 37.6^{\circ} \mathrm{E} ; 156 \mathrm{~m}\right.$ a.s.l.) during DecemberFebruary and the $500 \mathrm{hPa}$ heights (a) and sea-level pressures (b) over the NMC gridpoints. Isopleths are given at intervals of 0.1; solid line represents positive values, and dashed lines negative values. The $95 \%$ significance level is 0.11 . 

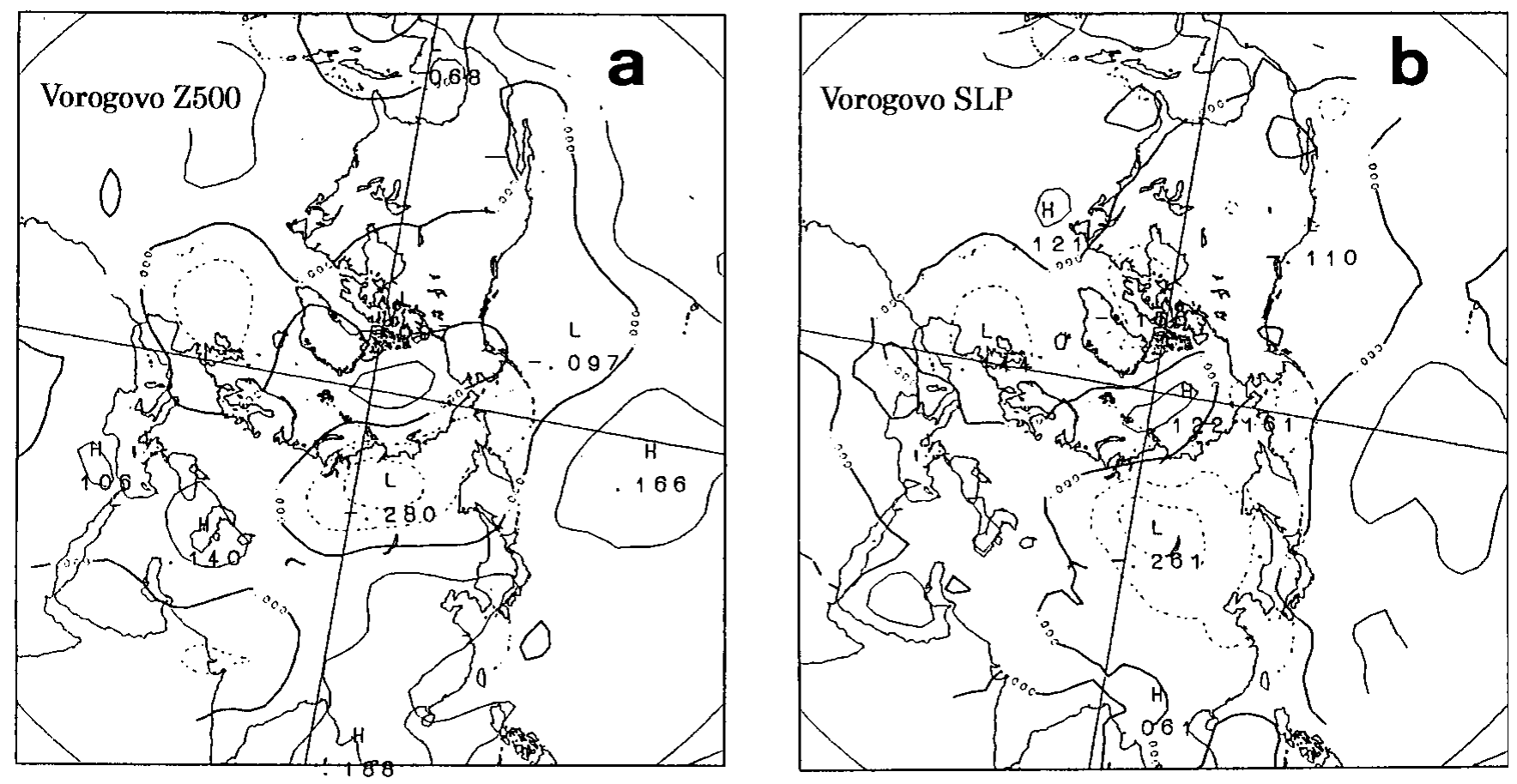

Fig. 11. Correlation coefficients between the snowfall intensities at Vorogovo $\left(61.0^{\circ} \mathrm{N}, 89.6^{\circ} \mathrm{E} ; 46 \mathrm{~m}\right.$ a.s.l.) during $\mathrm{November-}^{-}$ January and the $500 \mathrm{hPa}$ heights $(a)$ and sea-level pressures $(b)$ over the $\mathcal{N} M C$ gridpoints. Isopleths are given at intervals of 0.1; solid line represent positive values, and dashed lines negative values. The 95\% significance level is 0.10 .

correlations are also seen in Figure 10a. In this case, however, the center of the high-correlation area is located to the northwest of Moskva, near the Baltic Sea coast. As is well known, the theory of baroclinic instability predicts that the vertical profile of the low-pressure center shows an inclination towards the upstream direction when the disturbance is developing. This means that the vector from the low-pressure center at the $500 \mathrm{hPa}$ height to that at sea level is equivalent to the mean direction of synoptic-disturbance propagation. In other words, low pressures causing snowfalls at Moskva generally come from the Baltic Sea. In a similar manner, it has been shown that snowfalls at most other stations in the European Russian plain are caused by traveling disturbances from the Baltic or North Sea.

Figure 1la and b show correlation coefficients between the snowfall intensities at Vorogovo (Yenisei river valley) during November-January and the $500 \mathrm{hPa}$ heights and sea-level pressures, respectively, over the Northern Hemisphere. High correlations are seen near the reference station, though correlation coefficients are a little lower. The center of negative correlation (low pressure) at sea level is located several hundred kilometers east of Vorogovo, and then northwesterly winds are expected at Vorogovo. From the vector from the low-pressure center at the $500 \mathrm{hPa}$ height to that at sea level, we see that disturbances come down from the Arctic Ocean and cause snowfalls at Vorogovo. Similar trends have been found at other stations along the Yenisei river valley, and it is concluded that heavy snowfalls along the Yenisei river valley are caused by traveling disturbances from the Arctic Ocean and associated northwesterly winds.

It has also been shown by the same analysis that snowfalls at the eastern Siberian lowland along the Lena river valley are caused by traveling disturbances from the Arctic Ocean during October-December. However, the freezing of the Arctic Ocean is expected to suppress the generation of disturbances and the supply of water vapor from the ocean to the atmosphere. This may explain why snow accumulation becomes very weak in the Lena river valley after December (see Fig. 2).

\section{CONGLUDING REMARKS}

Historical snow-depth observations in the FSU during the period September 1960-August 1984 have been analyzed in order to understand the seasonal cycle of snow coverage in the FSU. Snow cover first appears in September in northeastern regions, and then moves relatively slowly to the south and west. The snow-covered area spreads over the entire territory before early January. The maximum snow depths are observed during mid-January to late March depending on the region. Snowmelt begins in the southern regions and then snow cover retreats rapidly northward until it disappears completely before late June.

Northward of $60^{\circ} \mathrm{N}$, the land surface is snow-covered for more than half the year. The longest snow-cover duration is observed on the central Siberian plateau (about 9.5 months) and along the Arctic coastal regions (about 8.5 months), and the shortest in the southwestern region near the Black and Caspian Seas (4 months or less). One of the most conspicuous features of the snow coverage in the FSU is that the length of the snow-accumulation period differs considerably from region to region (2-7 months), while the length of the snowmelt period is rather short and mostly uniform over the entire territory (1-2 months).

The maximum snow depths are $20-50 \mathrm{~cm}$ in most regions of the FSU, but they exceed $60 \mathrm{~cm}$ in the mountainous regions in central Siberia and Kamchatka peninsula, and also along the Yenisei river valley. In contrast, values of the maximum snow depths are very small in the European Russian plain and southwestern region. Both are 
located in the inland plain far away from the ocean. Values for the maximum snow depth are also very small along the Lena river valley, central Siberian lowland, in spite of the air temperature being extremely low in wintertime. Along the Lena river valley the maximum snow depths occur in October-November, and very little snow accumulation occurs after December.

Snowfall and snowmelt intensities in the FSU also show marked regional differences. Spatial correlation of the snowfall intensities is usually high only around the reference station, while the high-correlation zone for the snowmelt intensity extends widely parallel to the latitude of the reference station. This suggests that snowfall is controlled by atmospheric circulation and local topography rather than by air temperature, while snowmelt strongly depends on the solar radiation in springtime.

Correlation coefficients between the snowfall intensities and sea-level pressures or $500 \mathrm{hPa}$ heights clarified the meteorological conditions which bring heavy snowfalls. Deep snow depths along the Yenisei river valley are caused by frequent migration of synoptic disturbances from the Arctic Ocean during November-January. Snowfalls along the Lena river valley are also caused by traveling disturbances from the Arctic Ocean, but snow accumulation is suppressed after the sea water of the Arctic Ocean has been frozen. On the other hand, snowfalls in the European Russian plain are caused by traveling disturbances from the Baltic and North Seas.

Obviously, snowfall intensity is controlled by air temperature, specific humidity and atmospheric circulation. It is well known that intensive snowfalls in mountainous regions are caused by the rapid decrease in air temperature when air flows upward along the mountain slope. In the FSU, air temperature is usually very cold in wintertime and then ample water vapor must be transported by atmospheric circulation to bring intensive snowfalls. This would be realized if synoptic disturbances came from over the ocean. The above results have shown that traveling disturbances from the Arctic Ocean and Baltic and North Seas are most important for heavy snowfalls in the continental plains and inland basins. Conversely, this implies that snowfalls may be very small in the far inland plains where moisture transport by meteorological disturbances is less frequent (e.g. the European Russian plain and southwestern region).

\section{ACKNOWLEDGEMENT}

The authors would like to express their appreciation to the staff of the NSIDC who provided us with this important dataset.

\section{REFERENGES}

Barry, R. G., R. L. Armstrong and A. N. Krenke. 1993. An approach to assessing changes in snow cover: an example for the former Soviet Union. Proc. East. Snow Conf., 50th Annual Meeting, 8-10 June 1993, Québec, Que., Canada, 25-33.

Brown, R. D. 2000. Northern Hemisphere snow cover variability and change, 1915-97. f. Climate, 13(7), 2339-2355.

Fallot, J. M., R. G. Barry and D. Hoogstrate. 1997. Variations of mean cold season temperature, precipitation and snow depths during the last 100 years in the former Soviet Union (FSU). Hydrol. Sci. f., 42(3), $301-327$.

Hahn, D. G. and J. Shukla. 1976. An apparent relationship between Eurasian snow cover and Indian monsoon rainfall. f. Atmos. Sci., 33, 2461-2462.

Kripalani, R. H. and A. Kulkarni. 1999. Climatology and variability of historical Soviet snow depth data: some new perspectives in snow-Indian monsoon teleconnections. Climate Dyn., 15(6), 475-489.

Lydolph, P. 1977. Climates of the Soviet Union. New York, Elsevier. (World Survey of Climatology 7.)

Yang, S. and L. Xu. 1994. Linkage between Eurasian winter snow cover and regional Chinese summer rainfall. Int. F. Climatol., 14(7), 739-750.

Ye, H., H. R. Cho and P. E. Gustafson. 1998. The changes in Russian winter snow accumulation during 1936-83 and its spatial patterns. F. Climate, $11(5), 856-863$. 